\title{
Internal Herniation Incidence After RYGB and the Predictive Ability of a CT Scan as a Diagnostic Tool
}

\author{
Bart Torensma $^{1,2}$ (D) $\cdot$ Laurens Kooiman ${ }^{2} \cdot$ Ronald Liem $^{2} \cdot$ Valerie M. Monpellier $^{2} \cdot$ Dingeman J. Swank $^{2} \cdot$ Larissa Tseng $^{2}$
}

Received: 31 January 2020 / Revised: 24 July 2020 / Accepted: 28 July 2020 / Published online: 3 August 2020

(C) The Author(s) 2020

\begin{abstract}
Purpose The clinical diagnosis of an internal herniation (IH) after a Roux-en-Y Gastric Bypass (RYGB) remains difficult; therefore, performing a CT scan is usually part of the diagnostic process. The goal of this study was to assess the incidence of $\mathrm{IH}$ in patients with open and closed MD (mesenteric defect) and to study if the ability to diagnose an IH with a CT scan is different between these groups.

Materials and Methods IH was defined as a visible intestine through the mesenteric defect underneath the jejunojejunostomy and/or in the Petersen's space. CT scan outcomes were compared with the clinical diagnosis of an IH. Until 31 June 2013, standard care was to leave mesenteric defects (MDs) open; after this date, they were always closed.

Results The incidence of IH in the primarily non-closed group was 3.9\%, and in the primarily closed group, this was $1.3 \%$ ( $p=$ 0.001 ). In group $\mathrm{A}$ (non-closed MD and $\mathrm{CT}$ ), the sensitivity of the $\mathrm{CT}$ scan was $80 \%$, and specificity was $0 \%$. In group $\mathrm{C}$ (closed MD and CT), the sensitivity was $64.7 \%$, and specificity was $89.5 \%$. In group B (non-closed, no CT), an IH was visible in $58.7 \%$ of the cases and not in $41.3 \%$. In group D (only a re-laparoscopy), an IH was visible in 34.3\% of the cases and not in $65.7 \%$. Conclusions Using the CT scan in suspected IH is not useful in if the MDs were not closed. If the MDs were closed, then a CT scan is predictive for the diagnosis IH.
\end{abstract}

Keywords Bariatric surgery $\cdot$ Morbid obesity $\cdot$ RYGB $\cdot$ Internal herniation $\cdot$ CT scan $\cdot$ Incidence $\cdot$ Diagnostic tool

\section{Purpose}

The internal herniation (IH) is a well-known late complication of the Roux-en-Y gastric bypass (RYGB). Since the introduction of this complication in a case report in 1999 by Serra et al. [1], numerous publications have been dedicated to IH incidence, prevention, and diagnostics. Despite these publications, the clinical diagnosis of an IH remains challenging. Moreover, there is still no consensus on standardized closing of mesenteric defects (MD) and the use of a computer tomography (CT) scan for the diagnosis of the IH [2-10].

In daily practice, the $\mathrm{CT}$ scan is widely used as a diagnostic tool for $\mathrm{IH}$. Most previous trials validating the $\mathrm{CT}$ scan for

Bart Torensma

info@barttorensma.nl

1 Department of Anaesthesiology, Leiden University Medical Center, Leiden, The Netherlands

2 Department of Surgery, Dutch Obesity Clinic West \& LUMC, The Hague, The Netherlands detecting IH show a large variety in sensitivity and specificity, and have low power due to too few inclusions or algorithm for detecting IH from a CT scan $[9,11-17]$. Thus, the value of the $\mathrm{CT}$ scan in IH diagnostics is unclear. Furthermore, it is also uncertain whether the sensitivity and specificity of the CT scan are different when mesenteric defects were closed or left open.

Only three studies with a large population and assumable enough power have shown results towards a better understanding of the effect of the CT scan on detecting IH. Since 2018, two large trials in 1475 bariatric patients showed that the CT scan had a specificity of $87.1 \%$ and a high negative predictive factor of $96.8 \%[18,19]$. Also, a study [20] found in $40.2 \%$ of the time an IH on the CT scan, and at the same time, the study could in $61.1 \%$ objectify this finding during surgery.

However, up to date, there is still discussion as to whether closing the MD leads to a lower incidence of $\mathrm{IH}$ and what the role of a CT scan is in the diagnostic algorithm. Our clinic changed its policy in 2013 from leaving MD open to standardly closing the mesenteric defects. This gives us the opportunity to study the incidence of $\mathrm{IH}$ in patients with and without 
closed MD. In addition, we can assess whether the accuracy of a CT scan is different in patients with and without closed MD.
- Group C is the closed group who underwent a CT.

- Group D is the closed group without CT scan.

\section{Materials and Methods}

\section{Study Population}

This is a retrospective single-center cohort study. All patients who underwent a primary laparoscopic RYGB between January 2011 and December 2016 were selected from hospital electronic databases. All patients gave informed consent at the start of the treatment. All data were used anonymously.

\section{Standard Treatment}

All patients were screened and indicated according to the IFSO criteria prior to bariatric surgery. Patients received preand postoperative multidisciplinary counseling focused on long-term behavioral change [21]. This program has a 5-year follow-up.

Regarding the closure of the MD, standard policy changed during study period. Between January 2011 and June 2013, the MD were never closed when a RYGB was performed: the non-closed group. From July 2013 until December 2016, all mesenteric defects where closed with the stapler device EMS from Johnson \& Johnson: the closed group. Halfway this second period, the clinic changed towards the hernia stapler Universal by Medtronic. The same technique was used, and, in both devices, there were no differences in the height of the staples. Patients were operated by four surgeons; all have performed more than 2000 RYGBs and sleeves since 2011 until now (2019).

\section{Patient Selection}

Patients were retrospectively selected from the electronic hospital database to see if they had undergone a re-laparoscopy after RYGB or not.

A patient was selected if it was announced at the emergency department with complaints with intermitted pain in the upper (left) abdomen, related to complaints after a meal with or without other obstruction complaints. If so, they got a reoperation through a re-laparoscopy. A CT scan was done in cases whereby the complaints could predict alternative diagnoses.

A CT scan was done as check and always diagnosed by a radiologist who reported this in the patient electronic file. Reoperation was done in $100 \%$ of the cases. For analysis, patients were divided in four groups:

- Group A is the non-closed group who underwent a CT

- Group B is the non-closed group without CT.

\section{Internal Herniation}

An IH was diagnosed during re-operation if they met the following criteria:

1. Internal hernia, defined as the presence of herniated small bowel with or without obstruction or ischemia through visible opening in the MD underneath the jejunojejunostomy and/or the Petersen's space. Incidental IHs, found at laparoscopies conducted for uncertain abdominal pain, were included as having IH.

2. Suspected intermittent IH defined as clinical suspicion of $\mathrm{IH}$ and/or signs on CT scan, but at laparoscopy presenting open mesenteric defects without intestinal loop.

3. For the incidence calculation, the findings of the surgeon during the operation were used and compared with the findings of the radiologist report.

\section{Patient Characteristics}

Obtained data included age, sex, preoperative weight, postoperative weight, IH presence, $\mathrm{IH}$ in date, and time period. Body mass index (BMI) and percentage total weight loss (\%TWL) were calculated.

\section{Individual Differences Calculation Between Surgeons}

Since an operation is a human action, variation of closing technique could predict the incidence of an IH. Therefore, the incidence of IH was tested and calculated for each of the four surgeons.

\section{Data Capture}

The analysis was performed on a blinded data set after a medical/scientific review was completed, and all protocol violations have been identified and the data set was declared complete. All data were collected in a data management system (Castor EDC, Amsterdam, The Netherlands; https:// www.castoredc.com) and handled according to Good Clinical Practice guidelines, Data Protection Directive certificate and complies with Title 21 CFR Part 11. Furthermore, the datacenter where all the research data is stored is ISO27001- and ISO9001-certified and Dutch NEN7510-certified. 


\section{Statistics}

For analyses, descriptive statistics and inferential statistics were used. All data was first tested for normality by a Kolmogorov-Smirnov test, a Q-Q plot, and Levene's test.

Categorical variables were expressed as $n(\%)$. Continuous normally distributed variables were expressed by their mean and standard deviation, not normally distributed data by their median and min-max range for skewed distributions. To test groups, categorical variables were tested using the Pearson chi-square test or Fisher exact test, when appropriate. Normally distributed continuously unpaired data were tested with the independent samples Student's $t$ test and, in case of skewed data, with the independent samples Mann-Whitney $U$ test.

Normally distributed continuously paired data were tested with the dependent samples Student $t$ test and, in case of skewed data, with the Wilcoxon signed-rank test.

Intraclass correlations and sensitivity/ specificity were calculated on specific data in the set. Moreover, an intraclass correlation test was performed to check the difference between surgeons, with regard to incidence of IH. Significance level was set at $p$ value $<0.05$.

Statistical analysis was performed using $\mathrm{R}$ studio statistical software (version 1.0.153).

\section{Sensitivity and Specificity}

In this study, statistics about sensitivity and specificity is described as follows:

Sensitivity: With a high sensitivity, you can assume that a patient is really not ill with a negative test result and can therefore go home. When the sensitivity decreases, the number of false negatives will increase.

Specificity: With a high specificity, you can assume that a patient is really ill with a positive test result and you can start treatment. When the specificity decreases, the number of false positives will increase.

In this manuscript, the focus will be on "yes" or "no" starting a treatment and therefore the specificity of the results.

\section{Results}

\section{Baseline Demographics}

Between the period of January 2011 and December 2016, 3262 patients underwent a RYGB. The database study found a total of 133 patients $(4.1 \%)$ who were re-operated for suspected IH and were included in this study. Most of these patients were female $119(89.5 \%)$. Mean \pm SD age was 44.56 \pm 9.7 years old. The mean \pm SD preoperative BMI before bariatric surgery was $43.3 \pm 12.1 \mathrm{~kg} / \mathrm{m}^{2}$. At the day of re- operation, the mean \pm SD BMI was $29.7 \pm 6.5 \mathrm{~kg} / \mathrm{m}^{2}$ and TWL was $31.1 \%$. The average time between RYGB and IH was $17.98 \pm 11.2$ months.

There were no significant differences in baseline characteristics between the patients who were diagnosed or suspected with $\mathrm{IH}$ and the patients who were not.

In 56 patients (42.1\%), the re-operation was performed in an acute phase, and in 77 patients (57.9\%), elective surgery was scheduled $(p=0.351)$. In nine cases $(6.8 \%)$, laparoscopy was converted because of insufficient exposure. All other cases $(n=124 / 93.2 \%)$ were successfully performed laparoscopically $(p=0.03)$.

\section{Closed Versus Open Mesenteric Defects}

Between January 2011 and June 2013 (MD left open), 1058 patients underwent a RYGB; 62 of these patients were suspected of IH and underwent a re-operation. In the group of patients with closed MD ( $N=2204), 71$ patients underwent a re-operation. Thus, the incidence of re-operation in the nonclosed group was significantly higher $(5.8 \%)$ than that in the closed group $(3.2 \%, p=0.001)$. The incidence of $\mathrm{IH}$ was also significantly higher in non-closed group (3.9\%) compared with that in the closed group $(1.3 \%, p=0.001$, Fig. 1$)$.

\section{Computer Tomography Scan and Diagnosis of Internal Herniation}

Group A, non-closed group who underwent a CT scan, consisted of 16 patients. In this group, the sensitivity of the CT scan was $80 \%$ and specificity was $0 \%$. The positive predictive value of the CT scan in this group was $92 \%$, and the negative predictive value was $0 \%$.

Thus, with the high sensitivity, you can assume that a patient is really not sick with a negative test result and no treatment is possible and the patient can go home. When the sensitivity decreases, the number of false negatives will increase. The risk is that people who are sick will be sent home. Whereby, the positive predictive value indicates the afterchance of the presence of disease in people with a positive test result. Since we are interested in the fact of starting a treatment yes or no, statistical wise, we need to look at the specificity results.

Group B was the non-closed group who was re-operated without a performance of a CT scan $(N=46)$. In this group, an $\mathrm{IH}$ was visible during re-operation in $58.7 \%$ of the cases, and in $41.3 \%$, it was not.

Group C was the closed group in whom a CT scan was performed $(N=36)$. In group $\mathrm{C}$, the sensitivity of the $\mathrm{CT}$ scan was $64.7 \%$ and specificity of $89.5 \%$, and a positive predictive value of $84 \%$ and a negative predictive value of $74 \%$. Thus, with a high specificity, you can assume that a patient is really ill with a positive test result and you can start the treatment. 
Fig. 1 Group A is the non-closed group who underwent a CT.

Group B is the non-closed group without $\mathrm{CT}$. Group $\mathrm{C}$ is the closed group who underwent a CT. Group D is the closed group without CT scan. MD, mesenteric defects; $\mathrm{IH}$, internal herniation
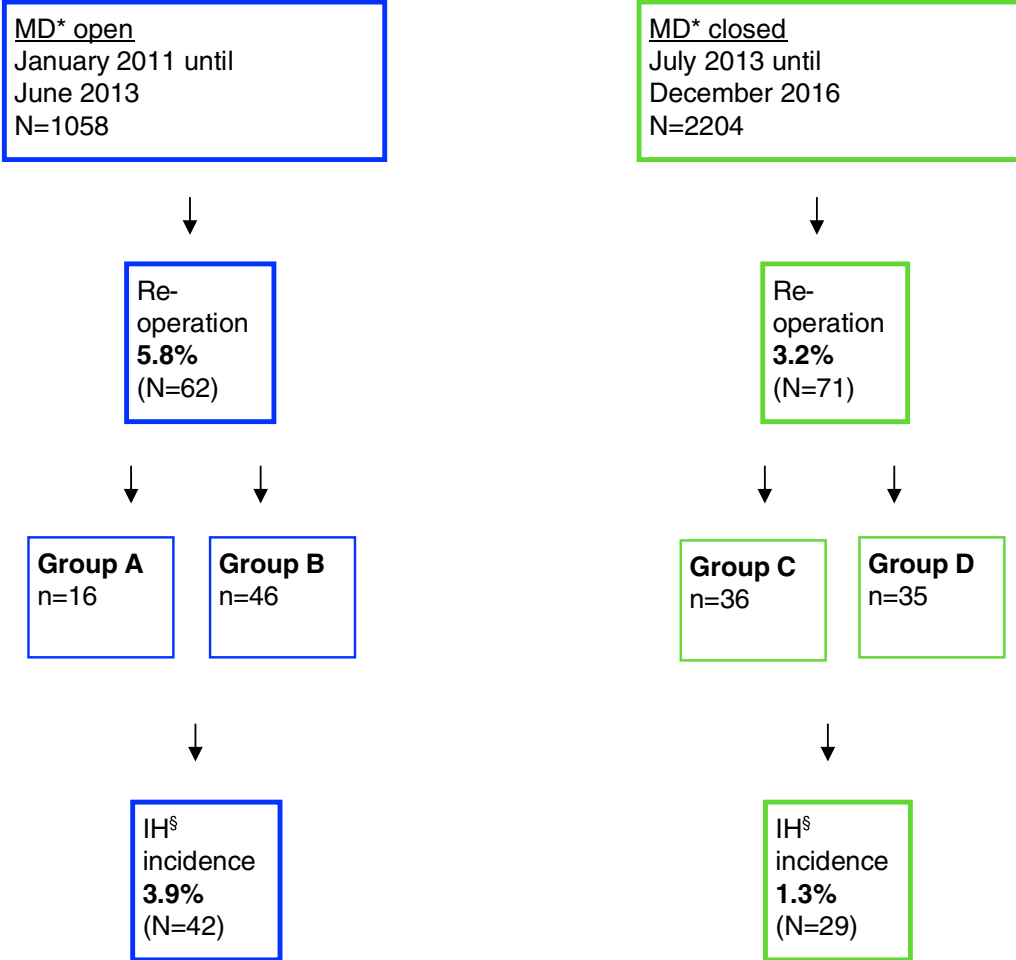

-Group $A$ is the non-closed group who underwent a CT -Group B is the non-closed group without CT.

-Group $C$ is the closed group who underwent a CT.

-Group D is the closed group without CT scan.

${ }^{*} \mathrm{MD}=$ Mesenteric defect

$\S \mathrm{IH}=$ Internal Herniation

Group D was the closed group without CT scan $(N=35)$. In group $\mathrm{D}$, where only a re-operation was done, an $\mathrm{IH}$ was visible in $34.3 \%$ of the patients, and in $65.7 \%$, it was not.

\section{Follow-up}

In group $\mathrm{A}, 81.3 \%$ of patients were symptom-free after reoperation; this was $76.1 \%$ in group $\mathrm{B}, 61.1 \%$ in group $\mathrm{C}$, and $60.0 \%$ in group D. Thus, a total of 42 patients had $\mathrm{IH}$ surgery but still suffered from abdominal pains afterwards.

\section{Intraclass Correlation Between Surgeons and IH Occurring}

A total of $27.1 \%$ of the IH occurred in patients who were operated by surgeon $\mathrm{A}$; in patients who were operated by surgeons B, C, and D, a total of $24.3 \%$ of the patients developed an IH. The intraclass correlation was $98 \%(p=>0.05)$. Thus, there was no difference in incidence of $\mathrm{IH}$ occurring between the four surgeons and their surgical technique.

\section{Discussion}

The goal of this study was to assess the incidence of IH in patients with open and closed MD and to study if the ability to diagnose an $\mathrm{IH}$ with a $\mathrm{CT}$ scan was differed between these groups. In the Netherlands, the policy within bariatric surgery is that every patient will go back towards their treating hospital. Lost to follow, when complaints occur up on internal herniation, is therefore not possible in our database. Every surgeon saw their own patient postoperatively.

The results showed that the incidence of IH was significantly lower in patients with closed MD. Our data show that the incidence of IH can be significantly reduced by closing the MD: the incidence dropped from 3.9 to $1.3 \%$. These results are comparable with other studies [2, 22-27].

This study had a quite low incidence of $\mathrm{IH}$ in patients with open MD. It was $3.9 \%$ compared with $11.7 \%$ in the study by Aghajani et al., which is considered the golden standard [27]. Both studies had enough power $(N=3226$ versus 4013) and over 5 years follow-up (2005/2015 compared with this study 2011/2017). Therefore, we cannot explain the differences. 
Previous research focused on the $\mathrm{CT}$ scan in IH diagnostics [10-17]. However, none of these studies assessed the difference in CT accuracy comparing patients with open and closed MD in a clinical setting. Our results showed that the diagnostic accuracy of a CT scan in supporting the choice of treatment is not useful in patients with an open MD. In this group the CT scan had a specificity of $0 \%$; this means the risk is very high that people are operated while they do not have an IH. The possible explanation for the low predictive value of the CT scan in this group may be that the intestines move more freely (i.e., higher change for intermittent $\mathrm{IH}$ ). So, it could be that during the $\mathrm{CT}$ scan, there was an $\mathrm{IH}$, but when performing the laparoscopy, the intestines were returned to their normal anatomic situation.

In the closed group, the CT scan had a very high specificity (89\%). When patients in the closed group were directly operated without performing a CT scan, there was a large group (65.7\%) who did not have an IH and the re-operation performed was "unnecessary." Considering these results, in combination with the high specificity of the CT scan in this group, we recommend performing a CT scan when a patient with closed MD is suspected of IH.

It is important to appreciate that a $\mathrm{CT}$ scan can never rule out an IH completely. Thus, if symptoms of an IH remain, a laparoscopy is inevitable to exclude an $\mathrm{IH}$ as cause of the complaints.

After the correction of the $\mathrm{IH}$ and closure of the $\mathrm{MD}$, it was striking that three out of ten patients still had abdominal complaints. This suggests that, in addition to the $\mathrm{IH}$, there are other, possible unknown causes for abdominal pain after RYGB. A study with the results of 5 years postoperative after bariatric surgery showed that chronic abdominal pain was reported by $33.8 \%$. Also, symptoms of indigestion and irritable bowel syndrome were reported by $48.8 \%$ and $29.1 \%$ [28]. Multi-center/ country prospective long-term follow-up studies are necessary to understand the causes of these abdominal complaints.

Especially since the ability of scoring pain and the perception of pain is different in patients with obesity compared with patients without obesity [29]. This may have a significant effect on pain treatment and consequently needs to be taken into account when treating the patients with obesity for acute or chronic pain $[29,30]$.

A limitation of this study is the fact that this is a retrospective cohort; we have no knowledge of the current abdominal complaints of the patients who were not free of symptoms after re-operation. The fact that a CT scan was not performed in all patients could be perceived a limitation. Moreover, the results give us new insights on operating for suspected $\mathrm{IH}$ when mesenteric defects are primarily closed or open.

\section{Conclusion}

The incidence of IH can be significantly reduced by closing the mesenteric defects. The diagnostic accuracy of a CT scan in supporting the choice of treatment is not useful in a patient with open MD. However, when a patient with closed MD is suspected of IH, a CT scan can be predictive for the diagnosis of an $\mathrm{IH}$.

After the correction of an internal herniation, three out of ten patients still have postoperative complaints. This suggests that, in addition to an $\mathrm{IH}$, there are other causes for abdominal pain after RYGB.

Acknowledgments We thank the surgeons $\mathrm{M}$. Knook $(\mathrm{MD}, \mathrm{PhD})$ and $\mathrm{I}$. Janssen (MD) for their assistance, feedback, and advice during the study.

\section{Compliance with Ethical Standards}

Conflict of Interest The authors declare that they have no conflict of interest.

Ethical Approval All procedures performed in studies involving human participants were in accordance with the ethical standards of the institutional and/or national research committee and with the 1964 Helsinki declaration and its later amendments or comparable ethical standards.

Informed Consent For this type of study, formal consent is not required.

Open Access This article is licensed under a Creative Commons Attribution 4.0 International License, which permits use, sharing, adaptation, distribution and reproduction in any medium or format, as long as you give appropriate credit to the original author(s) and the source, provide a link to the Creative Commons licence, and indicate if changes were made. The images or other third party material in this article are included in the article's Creative Commons licence, unless indicated otherwise in a credit line to the material. If material is not included in the article's Creative Commons licence and your intended use is not permitted by statutory regulation or exceeds the permitted use, you will need to obtain permission directly from the copyright holder. To view a copy of this licence, visit http://creativecommons.org/licenses/by/4.0/.

\section{References}

1. Serra C, Baltasar A, Bou R, et al. Internal hernias and gastric perforation after a laparoscopic gastric bypass. Obes Surg. 1999;9: 546-9.

2. Paroz A, Calmes JM, Giusti V, et al. Internal hernia after laparoscopic Roux-en-Y gastric bypass for morbid obesity: a continuous challenge in bariatric surgery. Obes Surg. 2006;16:1482-7. Available from: http://www.ncbi.nlm.nih.gov/pubmed/17132415. Accessed 23 Oct 2014.

3. de la Cruz-Muñoz N, Cabrera JC, Cuesta M, Hartnett S, Rojas R. Closure of mesenteric defect can lead to decrease in internal hernias after Roux-en-Y gastric bypass. Surg Obes Relat Dis. Elsevier Inc.; 2011 [cited 2014 Oct 23];7:176-80. Available from: http://www. ncbi.nlm.nih.gov/pubmed/21126922. 23 Oct 2014.

4. de Bakker JK, van Namen YWB, Bruin SC, et al. Gastric bypass and abdominal pain: think of Petersen hernia. J Soc Laparoendosc Surg. 2012;16:311-3. Available from: http://www.ncbi.nlm.nih.gov/pmc/ articles/PMC3481246/. Accessed 18 Feb 2019.

5. Obeid A, McNeal S, Breland M, et al. Internal hernia after laparoscopic Roux-en-Y gastric bypass. J Gastrointest Surg. 2014;18: $250-6$. 
6. Ortega J, Cassinello N, Sánchez-Antúnez D, et al. Anatomical basis for the low incidence of internal hernia after a laparoscopic Rouxen-Y gastric bypass without mesenteric closure. Obes Surg. 2013;23:1273-80.

7. Geubbels N, Röell EA, Acherman YIZ, et al. Internal herniation after laparoscopic Roux-en-Y gastric bypass surgery: pitfalls in diagnosing and the introduction of the AMSTERDAM classification. Obes Surg. 2016;26:1859-66. Available from:. https://doi.org/ 10.1007/s11695-015-2028-5.

8. Geubbels N, Lijftogt N, Fiocco M, et al. Meta-analysis of internal herniation after gastric bypass surgery. Br J Surg. 2015;102:45160 .

9. Stenberg E, Szabo E. Comparing techniques for mesenteric defects closure in laparoscopic gastric bypass surgery - a register-based cohort study. Obes Surg. 2019;29:1229-35.

10. Stenberg E, Szabo E, Ågren G, et al. Closure of mesenteric defects in laparoscopic gastric bypass: a multicentre, randomised, parallel, open-label trial. Lancet. 2016;387:1397-404.

11. Onopchenko A. Radiological diagnosis of internal hernia after Roux-en-Y gastric bypass. Obes Surg. 2005;15:606-11.

12. Iannuccilli JD, Grand D, Murphy BL, Evangelista P, Roye GD, Mayo-Smith W. Sensitivity and specificity of eight CT signs in the preoperative diagnosis of internal mesenteric hernia following Roux-en-Y gastric bypass surgery. Clin Radiol. The Royal College of Radiologists; 2009;64:373-80. Available from: https://doi.org/ 10.1016/j.crad.2008.10.008.

13. Frøkjær JB, Jensen WN, Holt G, Omar HK, Olesen SS. The diagnostic performance and interrater agreement of seven CT findings in the diagnosis of internal hernia after gastric bypass operation. Abdom Radiol. Springer US; 2018;43:1-7. Available from: https://doi.org/10.1007/s00261-018-1640-y.

14. Park J, Chung M, Teixeira J, et al. Computed tomography findings of internal hernia after gastric bypass that may precede small bowel obstruction. Hernia. Springer Paris. 2016;20:471-7.

15. Altieri MS, Pryor AD, Telem DA, Hall K, Brathwaite C, Zawin M. Algorithmic approach to utilization of CT scans for detection of internal hernia in the gastric bypass patient. Surg Obes Relat Dis. Elsevier; 2015;11:1207-11. Available from: https://doi.org/10. 1016/j.soard.2015.02.010.

16. Zhang G, Cai MBY, Xu MBG. Diagnostic accuracy of MRI for diagnosis of internal hernia in pregnant women with prior Roux-enY gastric bypass. Am J Roentgenol. 2018;211:789-99.

17. Klop C, Deden LN, Aarts EO, et al. Diagnosing internal herniation after Roux-en-Y gastric bypass surgery: literature overview, cadaver study and the added value of 3D CT angiography. Obes Surg. 2018; 28:1822-30.

18. Ederveen JC, van Berckel MMG, Nienhuijs SW, et al. Predictive value of abdominal $\mathrm{CT}$ in evaluating internal herniation after bariatric laparoscopic Roux-en-Y gastric bypass. Br J Surg. 2018;105: 1623-9.

19. Ederveen JC, van Berckel MMG, Jol S, et al. Diagnosing internal herniation after laparoscopic Roux-en-Y gastric bypass: usefulness of systematically reviewing CT scans using ten signs. Eur Radiol. European Radiology. 2018;28:3583-90.

20. Wijngaarden LH, Van Veldhuisen SL, Klaassen RA, et al. Predicting symptom relief after reoperation for suspected internal herniation after laparoscopic Roux-en-Y gastric bypass. Obes Surg. 2018;28:3801-8.

21. Tettero OM, Aronson T, Wolf RJ, et al. Increase in physical activity after bariatric surgery demonstrates improvement in weight loss and cardiorespiratory fitness. Obes Surg. 2018;28:3950-7.

22. Iannelli A, Facchiano E, Gugenheim J. Internal hernia after laparoscopic Roux-en-Y gastric bypass for morbid obesity. Obes Surg. 2006;16:1265-71.

23. Cho M, Pinto D, Carrodeguas L, et al. Frequency and management of internal hernias after laparoscopic antecolic antegastric Roux-en$\mathrm{Y}$ gastric bypass without division of the small bowel mesentery or closure of mesenteric defects: review of 1400 consecutive cases. Surg Obes Relat Dis. 2006;2:87-91.

24. Kristensen SD, Floyd AK, Naver L, Jess P. Does the closure of mesenteric defects during laparoscopic gastric bypass surgery cause complications? Surg Obes Relat Dis. Elsevier; 2015;11:459-65. Available from: https://doi.org/10.1016/j.soard.2014.10.013.

25. Danshøj Kristensen S, Jess P, Karen Floyd A, Eller A, Engberg A, Naver L. Internal herniation after laparoscopic antecolic Roux-en-Y gastric bypass: a nationwide Danish study based on the Danish National Patient Register. Surg Obes Relat Dis. Elsevier; 2016;12: 297-304. Available from: https://doi.org/10.1016/j.soard.2015.10. 059.

26. Aghajani E, Jacobsen HJ, Nergaard BJ, Hedenbro JL, Leifson BG, Gislason H. Internal hernia after gastric bypass: a new and simplified technique for laparoscopic primary closure of the mesenteric defects. J Gastrointest Surg. 2012 [cited 2014 Oct 23];16:641-5. Available from: http://www.pubmedcentral.nih.gov/articlerender. fcgi ?artid $=3274684 \&$ tool $=$ pmcentrez $\&$ rendertype $=$ abstract . Accessed 23 Oct 2014.

27. Aghajani E, Nergaard BJ, Leifson BG, et al. The mesenteric defects in laparoscopic Roux-en-Y gastric bypass: 5 years follow-up of non-closure versus closure using the stapler technique. Surg Endosc. Springer US. 2017;31:3743-8.

28. Høgestøl IK, Chahal-Kummen M, Eribe I, et al. Chronic abdominal pain and symptoms 5 years after gastric bypass for morbid obesity. Obes Surg. 2016; 27:1438-45.

29. Torensma B, Oudejans L, van Velzen M, et al. Pain sensitivity and pain scoring in patients with morbid obesity. Surg Obes Relat Dis. 2017;13:788-95.

30. Torensma B, Thomassen I, van Velzen M, et al. Pain experience and perception in the obese subject systematic review (Revised Version). Obes Surg. 2015; Available from:; https://doi.org/10. 1007/s11695-015-2008-9.

Publisher's Note Springer Nature remains neutral with regard to jurisdictional claims in published maps and institutional affiliations. 